\title{
Assessment of the effect of climate change on the floods in Bulgaria
}

\author{
Rositsa Velichkova ${ }^{1,{ }^{*},}$ Radostina A. Angelova ${ }^{2}$, and Iskra Simova ${ }^{3}$ \\ ${ }^{1,3}$ Technical University of Sofia, Hydroaerodynamic and hydraulic machines Department, 1000 Sofia, \\ Bulgaria \\ ${ }^{2}$ Technical University of Sofia, Textile Department, 1000 Sofia, Bulgaria
}

\begin{abstract}
Global warming intensifies the water cycle. The intensified water cycle is considered to be among the reasons for the increment of floods in several regions on Earth. The floods and the ensuing disaster situations, which have increased over the past year, have caused massive material damage and economic losses to the Bulgarian population. The occurrence of floods was directly associated with the amount of rainfall in a given period. Therefore, the present study aims to assess the trends in rainfall changes in Bulgaria and their correlation with the floods over 8 years: from 2010 to 2017.
\end{abstract}

\section{Introduction}

In recent decades, climate change has been one of the most discussed topics in society. The Intergovernmental Panel on Climate Change [1] reported its aim to examine the studies and provide a balanced assessment of the available information on climate change and the potential for mitigation.

Global warming is one of the most visible manifestations of climate change. The $21 \mathrm{st}$ Century Climate Forecasts [1] are based on the results from numerical climate models that use available data for present and past periods and apply different scenarios. According to the most likely climatic predictions, for the period 2016-2035, the average global ground temperature would rise by $1^{\circ} \mathrm{C}$ above the average temperature for the period $1850-1900$, and $0.3^{\circ} \mathrm{C}$ to $0.7^{\circ} \mathrm{C}$ above the average for the period 1986-2005 [2]. The increase in average seasonal and average annual temperatures is expected to be higher in the tropics than in the average latitudes [3]. Therefore, different solutions have been in a search to overcome the problem, mainly in the field of energy utilization and energy efficiency [4-7].

Global warming intensifies the water cycle $[8,9]$ causing more rainfalls in areas, close to water sources (rivers, lakes, seas), and less precipitation in areas, away from water basins. The rain and snowfalls affect other elements of the water cycle, e.g., runoff and infiltration on soils and plants, thus influencing the groundwater and water storage. The climate becomes wetter and has its effect on humans and the ecosystem. Roshan et al. [10] have found that global warming influences the increment of precipitation, especially in cold periods (autumn and winter). Model simulations also show that average zonal precipitation is likely to increase in high and medium latitudes and is more likely to decrease in the tropics. 
The intensified water cycle is considered to be among the reasons for the increment of floods in several regions on Earth. The association between climate changes and floods has been studied in $[11,12]$. The research of Barnes [13] was dedicated to the record levels of rainfalls that provoked extensive floods in Cumbria. Bloschl et al. [12] discussed the need for a better understand of how global warming and climate change influence the type, frequency, and magnitude of floods, as well as their local distribution.

Though the difference between rainfalls in wet and dry areas and between wet and dry seasons would increase, there could be regional exceptions [14]. For the territory of the Balkan Peninsula, for example, no significant changes in average rainfall are expected (under favorable climate scenarios) [15]. The unfavorable scenarios predict a reduction of rainfall by $20-30 \%$ by the end of the 21 st century [15]. However, in society, the flood occurrence is directly associated with the amount of rainfall in a given period. Therefore, the present study aims to assess the trends in rainfall changes in Bulgaria and their correlation with the floods over 8 years (from 2010 to 2017).

\section{Trends of precipitation in Bulgaria}

Bulgaria occupies a significant part of the Balkan peninsula, having outlets on the Black Sea and Danube river. Its relief varies from sea level to $2925 \mathrm{~m}$ (Musala pick, the highest peak on the Balkan peninsula).

Seven districts were selected to assess the trends in the precipitation changes and their possible relation to the floods (Fig. 1): Burgas and Varna (Black sea coast), Vidin and Ruse (Danube river coastline), Blagoevgrad (west border), Kardzhali (south border) and Sliven (middle of the country, in the southern slopes of the Balkan mountain).

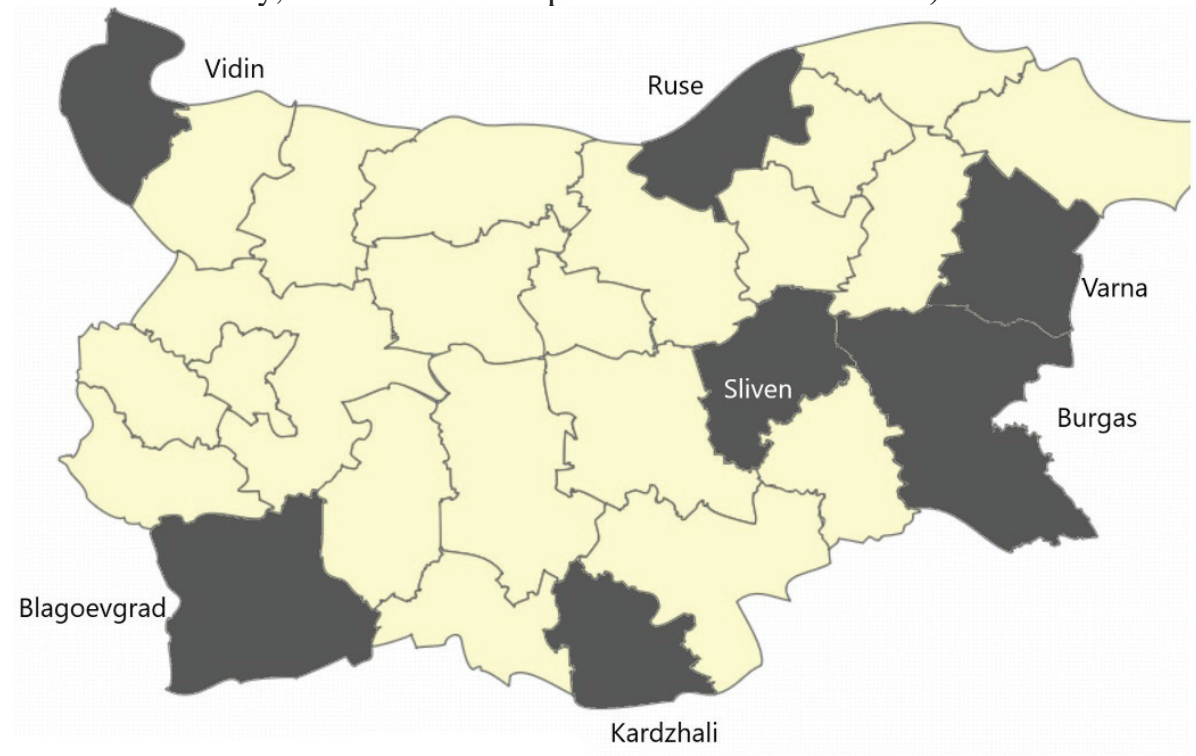

Fig. 1: Map of Bulgaria, selected districts

Figure 2 shows the trends in the rainfall in the selected regions for the period 20102017. The information is based on data taken from 21 weather stations [16]. The largest precipitations occurred in the year 2014, except for Blagoevgrad, where the rainfall pick was in 2012. Ruse region is also an exception, as the level of precipitations is almost constant for the period. 


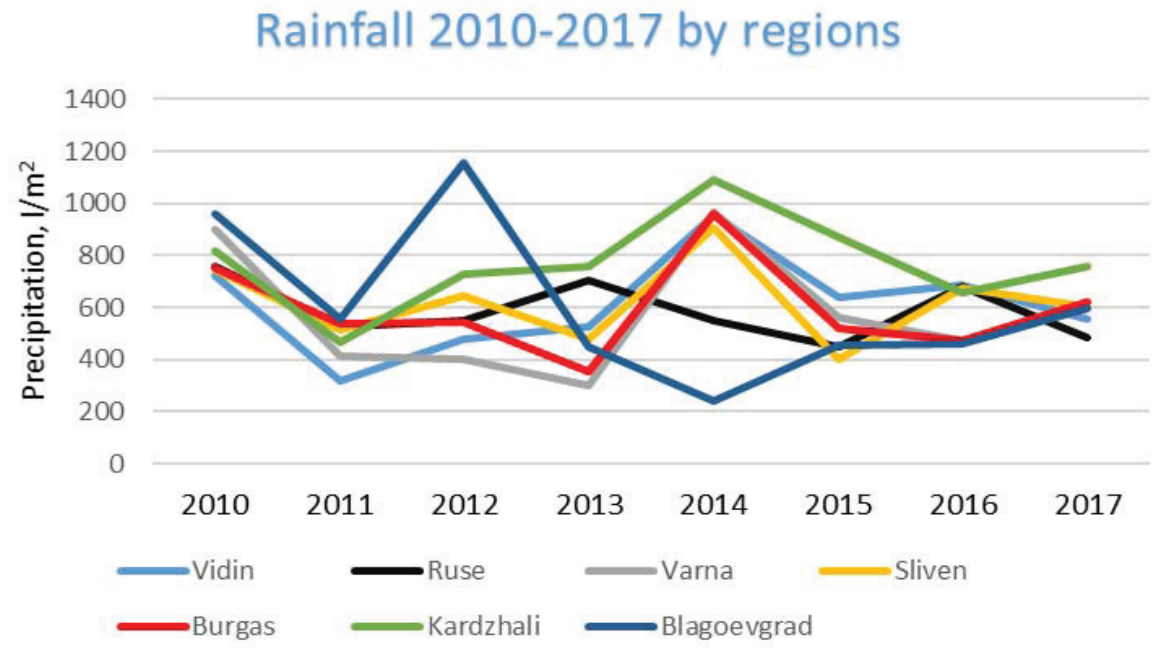

Fig. 2: Precipitation data in the selected regions for 2010-2017

It is considered that nearly $80 \%$ of the floods appear as a result of heavy rainfall, heavy snowmelt, riverbeds bottleneck [17]. The rest of the flood events are due to human activity and mistakes (accidents, breaking of dam lakes).

Problems that arise from floods affect different aspects of human life. The economic consequences directly or indirectly affect both the state and victims of the floods. Another problem is the spread of infections in the flooded territories. Last but not least, the change in the soil's ecological equilibrium has an impact on farmland and arable land, rivers, sequestered pitted water, as well as animal and plant species in the area. The floods and the ensuing disaster situations, which have increased over the past year, have caused massive material damage and economic losses to the Bulgarian population [18-19].

\section{Floods-precipitation relationship}

Statistical data [15] for the number of floods were used to assess the relationship between the quantity of rainfall by year and the number of flood hazards. Figures 3 to 9 present the comparison between the two sets of data for the seven districts.

\section{District of Vidin}

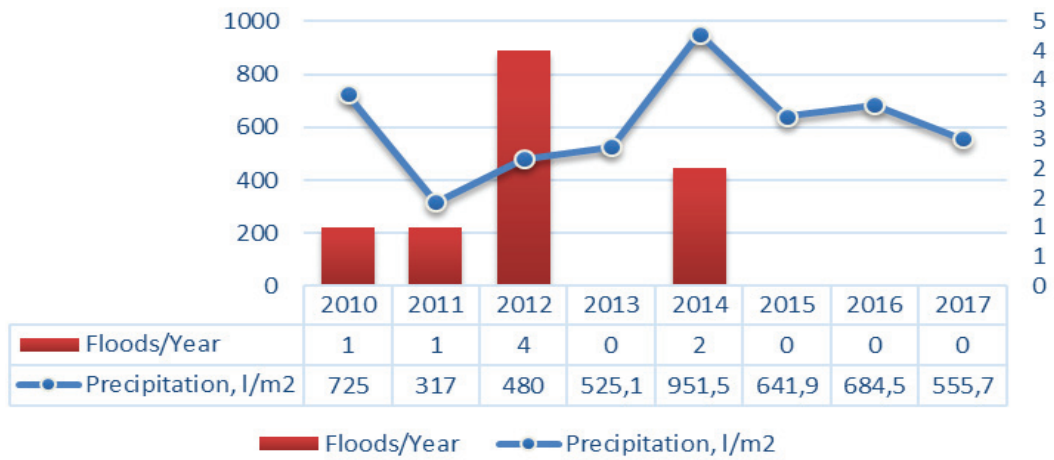

Fig. 3. District of Vidin: number of floods and precipitations per year 


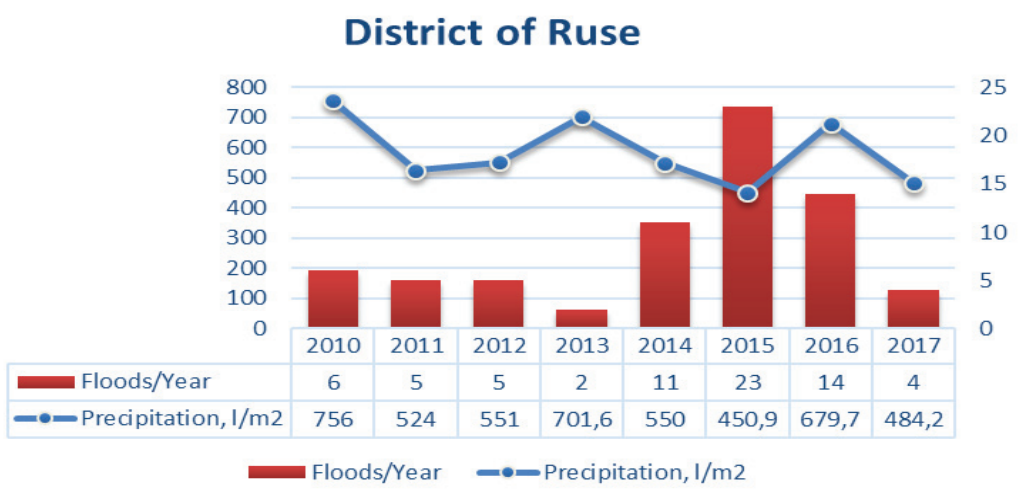

Fig. 4. District of Ruse: number of floods and precipitations per year

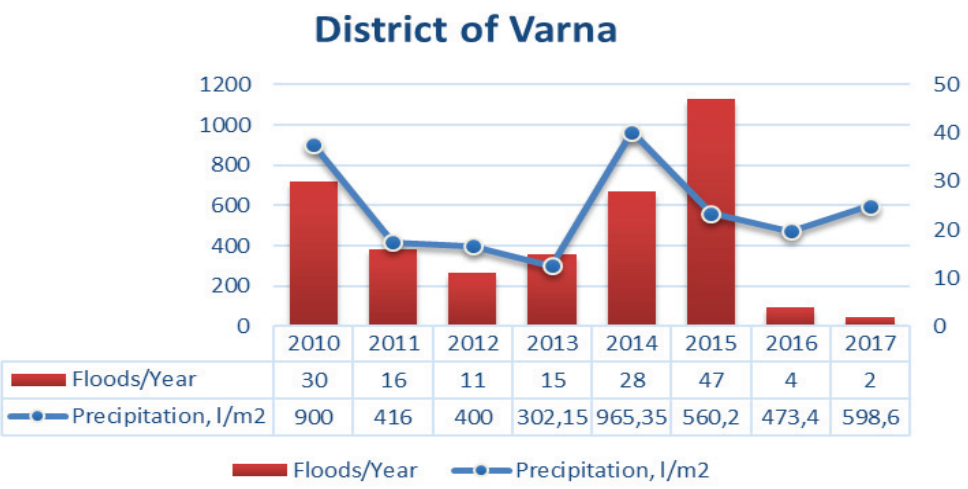

Fig. 5. District of Varna: number of floods and precipitations per year

\section{District of Burgas}

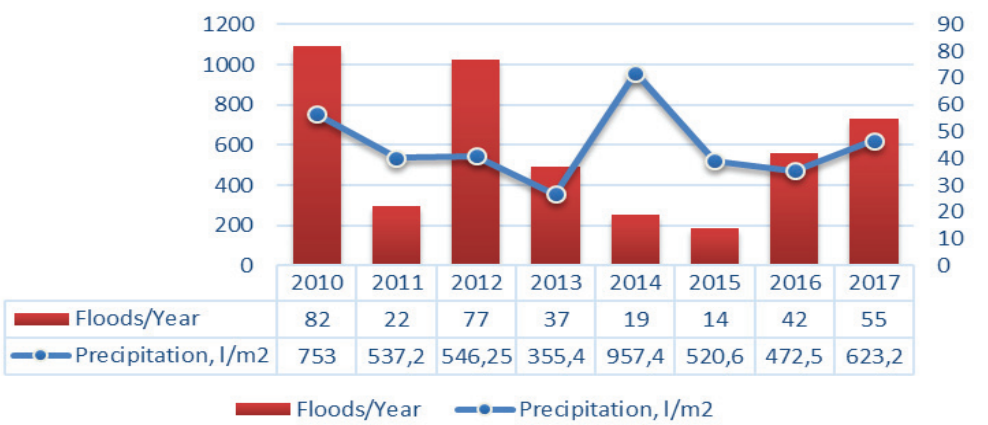

Fig. 6. District of Burgas: number of floods and precipitations per year

The figures show that a connection between precipitation and flooding on an annual basis can be hardly found. The rainfall picks in Burgas (Fig. 6) and Sliven (Fig. 7) in 2014, for example, do not correspond to the low number of floods for the year. The highest number of floods (876) for the period 2010-2017 occurred in Sliven (Fig. 7), but the rainfalls in the district for the same period are about the average for the country. 


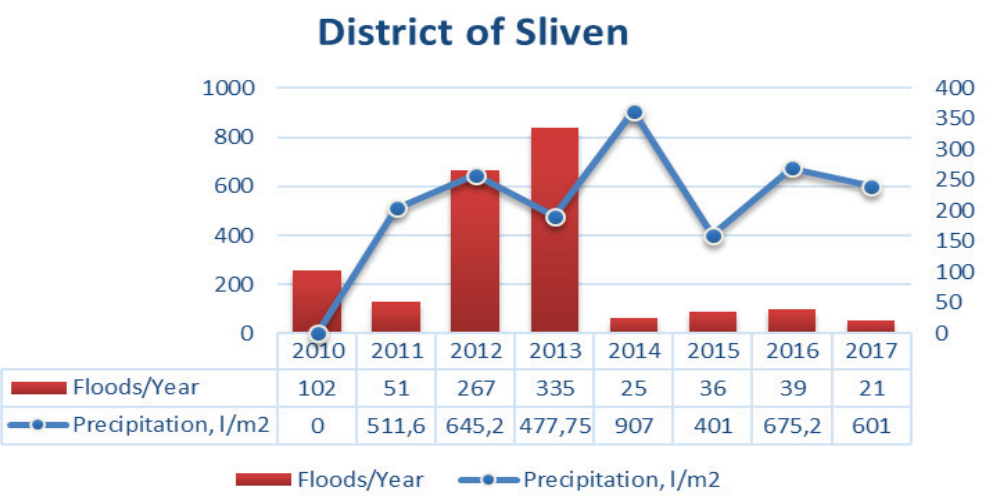

Fig. 7. District of Sliven: number of floods and precipitations per year

\section{District of Blagoevgrad}

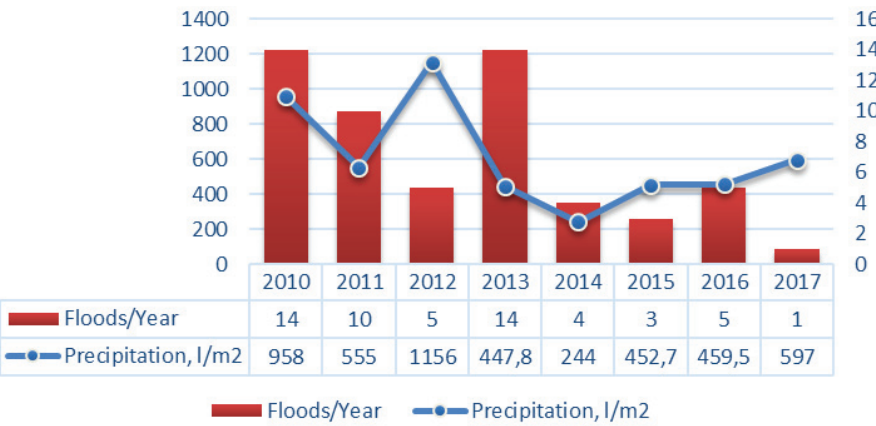

Fig 8. District of Blagoevgrad: number of floods and precipitations per year

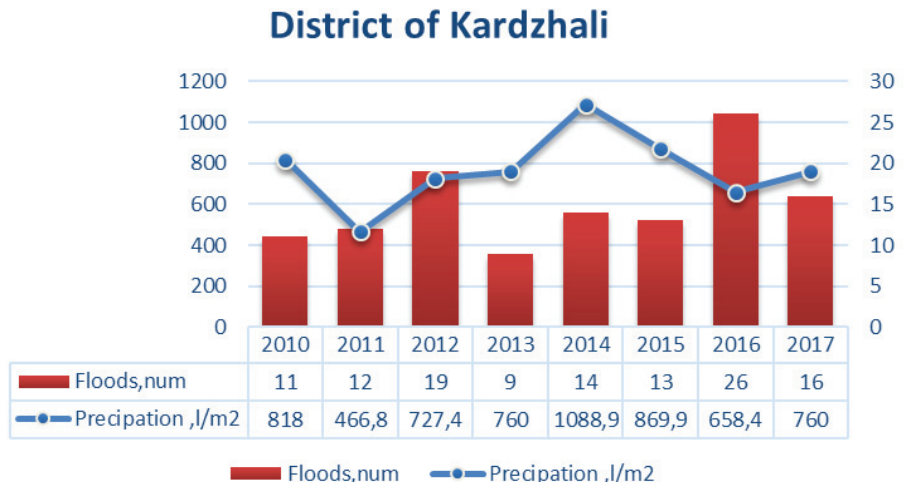

Fig. 9. District of Kardzhali: number of floods and precipitations per year

On the other hand, the least number of floods (8) occurred in the district of Vidin (Fig. 3 ), and the precipitation for the period is one of the largest. Most rainfalls are in Kardzhali (Fig. 9), but the number of floods there is among the average.

Regression analysis was applied to estimate the correlation between the number of floods in each district per year and the rainfall quantity per year. The results show that the coefficient of determination $r^{2}$ is highest in the districts of Varna $\left(r^{2}=0.18\right.$, Fig. 5) and Ruse 
$\left(r^{2}=0.13\right.$, Fig. 4). For other selected districts the coefficient of determination $r^{2}$ is less than 0.1 (Sliven, $r^{2}=0.06$, Fig. 7; Blagoevgrad, $r^{2}=0.04$, Fig. 8; Kardzhali, $r^{2}=0.03$, Fig. 9), being zero for the districts of Vidin (Fig. 3) and Burgas (Fig. 6). Obviously, there is no correlation between the two sets of data, as the coefficient of determination $\mathrm{r}^{2}$ is beside 1 .

The comparison between the number of floods per year and annual precipitation, together with the statistical analysis, lead to the conclusion that, besides the rainfall and the observation of likely climate change effects, there is no natural linkage between the studied phenomena. An explanation is that human intervention also stays behind the occurred floods.

\section{Perspectives}

The methods for solving the problem of devastating floods should be sought in different areas and directions. At a local level, work should be done for careful maintenance and control of the dams of the artificial lakes to prevent undue or excessive discharge when the water reaches a critical level.

The discharge of dam lake waters should be regulated and controlled. The discharge should occur during strictly defined periods to avoid rivers' overflowing.

A complementary measure at a local level is the regular cleaning of the riverbeds from both natural pollutants (wood, landslides, silt) and pollutants from human activity (household waste). Effective cleaning facilitates drainage and prevents the blocking of rivers.

A useful measure for floods reduction is the controlled felling of trees in slopes and gullies. The competent forestry authorities have to follow the relevant procedures against unauthorized and unlawful felling.

\section{Conclusions}

An analysis of the influence of global warming on precipitation in seven Bulgarian districts was made. The data for the annual rainfalls were compared with the data for the number of floods in the districts.

The statistical analysis showed that there is no correlation between the two sets of data. The conclusion that the increment/decrement of precipitations in the selected districts does not lead to change in the flood events on an annual basis is statistically proven.

This work has been carried out in the framework of the National Science Program "Environmental Protection and Reduction of Risks of Adverse Events and Natural Disasters", approved by the Resolution of the Council of Ministers № 577/17.08.2018 and supported by the Ministry of Education and Science (MES) of Bulgaria (Agreement № ДО-230/06-12-2018).

\section{References}

1. IPCC. Climate Change (2013): The Physical Science Basis. Cambridge, 2013.

2. G. Luber, J.Lemery, (Eds.). (2015). Global climate change and human health: From science to practice. John Wiley \& Sons.

3. V. Alexandrov, M.Schneider, E.Koleva,J. Moisselin,(2004). Climate variability and change in Bulgaria during the 20th century. Theoretical and Applied Climatology, 79(3-4), 133-149. 
4. M. Feijoó, J.Franco, J. Hernández, (2002). Global warming and the energy efficiency of Spanish industry. Energy Economics, 24(4), 405-423.

5. I. Ganev, I. Naydenova, B. Dimitrov, Development and implementation of the first system for efficient energy utilization of landfill gas in Bulgaria, 2nd Annual Meeting of the COST Action CM0901, "Detailed Chemical Kinetic Models For Cleaner Combustion", Saragossa, Spain. In Scientific report "Cleaner combustion" Eds: M. Abian and M.U. Alzueta, ISBN 978-84-615-3064-9, D.L Z-2976-2011.

6. I. Ganev, Energy Utilization of by-products derived from municipal solid waste, International conference Energy and climate change, Sofia, Hotel Holiday Inn, October 2010.

7. L. Davis, P. Gertler, (2015). Contribution of air conditioning adoption to future energy use under global warming. Proceedings of the National Academy of Sciences, 112(19), 5962-5967.

8. EPA. (2009). Climate change, United States Environmental Protection Agency. www.epa.gov, Accessed on 30 October, 2020

9. R. Velichkova, Ts. Petrova, I.Simova, G. Bardarov, D.Markov and M.Uzunova, (2020) Chapter 12 Water resource management in Bulgaria in Water Resources Management in Balkan Countries Editors: Negm, Abdelazim M., Romanescu, Gheorghe, Zelenáková, Martina (Eds.),Springer 2020 ISBN 978-3-030-22468-4

10. G. Roshan, A. Ghanghermeh, T. Nasrabadi, J.Meimandi, (2013). Effect of global warming on intensity and frequency curves of precipitation, case study of Northwestern Iran. Water resources management, 27(5), 1563-1579.

11. N. Schaller, A.Kay, R.Lamb, N.Massey, Van Oldenborgh, G. J., Otto, F. E., ... \& Bowery, A. (2016). Human influence on climate in the 2014 southern England winter floods and their impacts. Nature Climate Change, 6(6), 627.

12. G. Blöschl, J.Hall, A. Viglione, R.Perdigão, J. Parajka, B.Merz, M.Boháč, (2019). Changing climate both increases and decreases European river floods. Nature, 573(7772), 108-111.

13. A. Barnes, N.McCullen, T. Kjeldsen, (2019, September). Atmospheric origins of extreme rainfall in the UK. In 4th IMA International Conference on Flood Risk.

14. K. Trenberth, Dai, A., Van Der Schrier, G., Jones, P. D., Barichivich, J., Briffa, K. R., \& Sheffield, J. (2014). Global warming and changes in drought. Nature Climate Change, 4(1), 17.

15. Z. Popova, M. Ivanova,L. Pereira,V. Alexandrov, K.Doneva, P. Alexandrova, M. Kercheva,(2012). Assessing drought vulnerability of Bulgarian agriculture through model simulations. Journal of Environmental Science and Engineering. B, 1(8B), 1017 .

16. http://www.nsi.bg/bg/content/2915/наводнения, Accessed on 30 October, 2020

17. T. Tingsanchali, Urban flood disaster management. Procedia engineering, 32, 25-37. (2012)

18. V. Makakov, R.Velichkova, I. Simova, D. Markov, (2017, September). FLOODS RISK ASSESSMENT IN BULGARIA. In CBU International Conference Proceedings (Vol. 5, pp. 1253-1258).

19. R. Velichkova,(2020), Analysis of significant floods in Bulgarian Danube region,till 2010, IOP Conf. Series: Materials Science and Engineering 878 (2020) 012078, IOP Publishing, doi:10.1088/1757-899X/878/1/012078 